\title{
Dose-response association of dietary sodium intake with all-cause and cardiovascular mortality: a systematic review and meta- analysis of prospective studies
}

\author{
Alireza Milajerdi ${ }^{1}$, Kurosh Djafarian ${ }^{2}$ and Sakineh Shab-Bidar ${ }^{1, *}$ \\ 'Department of Community Nutrition, School of Nutritional Sciences and Dietetics, Tehran University of Medical \\ Sciences (TUMS), Tehran, Islamic Republic of Iran: ${ }^{2}$ Department of Clinical Nutrition, School of Nutritional Sciences \\ and Dietetics, Tehran University of Medical Sciences (TUMS), Tehran, Islamic Republic of Iran
}

Submitted 12 January 2018: Final revision received 6 June 2018: Accepted 27 June 2018: First published online 22 October 2018

\begin{abstract}
Objective: High $\mathrm{Na}$ intake has been associated with different health problems. However, serious controversies exist over studies investigating associations of $\mathrm{Na}$ intake with mortality from all-causes and CVD. The present systematic review and meta-analysis was done to investigate, for the first time, the dose-response association of dietary $\mathrm{Na}$ intake with all-cause and CVD mortality among prospective studies. Design: Relevant papers published up to August 2017 were searched in MEDLINE, EMBASE and Google Scholar databases. Prospective cohort studies on the association of dietary $\mathrm{Na}$ intake with all-cause or/and CVD mortality were included. Linear and non-linear dose-response associations between $\mathrm{Na}$ intake and CVD and all-cause mortality were examined.

Results: Overall, twenty publications met inclusion criteria. A significant non-linear association $(P<0 \cdot 001)$ was found between $\mathrm{Na}$ intake and CVD mortality risk among studies assessing urinary $\mathrm{Na}$ excretion, with a relatively steep slope at $\mathrm{Na}$ intakes above $2400 \mathrm{mg} / \mathrm{d}$. However, the association was not significant in studies using dietary $\mathrm{Na}$ intake $(P=0 \cdot 61)$. Additionally, the non-linear association of $\mathrm{Na}$ intake with all-cause mortality was also non-significant. No linear association (effect size; $95 \% \mathrm{CI} ; I^{2}$ ) was seen between $100 \mathrm{mg} / \mathrm{d}$ increment in Na intake and CVD mortality $(1.01 ; 0.97,1.05 ; 98.4 \%)$ or all-cause mortality $(1 \cdot 01 ; 1 \cdot 00,1.02 ; 89.2 \%)$. Following subgroup analyses, the association between $\mathrm{Na}$ intake and CVD mortality was observed only among studies conducted in the USA (0.99; 0.99, 1.00; 20.0\%). Conclusions: The study showed a direct association between urinary $\mathrm{Na}$ excretion and CVD mortality which was more considerable at intakes above $2400 \mathrm{mg} / \mathrm{d}$. In contrast, no significant association was found between $\mathrm{Na}$ intake and all-cause mortality. Further long-term prospective studies on different populations are required to confirm these findings.
\end{abstract}

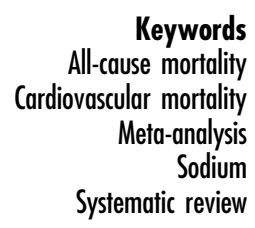

Among non-communicable diseases, CVD are the most common accounting for the largest fraction of deaths ${ }^{(1)}$. More than 17.3 million CVD-related deaths were reported in 2013, which represented a $41 \%$ increase over the prior three decades ${ }^{(2)}$. It should be noted that these deaths occur before the age of 60 years, resulting in substantial costs due to loss of human resources ${ }^{(3)}$. Therefore, primary and secondary prevention of CVD are very important to reducing CVD morbidity and even mortality.

Different lifestyle-related risk factors have been suggested to be related to CVD incidence and mortality ${ }^{(4)}$. Among these risk factors, diet is a critical one ${ }^{(5)}$. Studies have shown that adherence to a Western dietary pattern compared with a traditional diet will increase the risk of CVD events $^{(6)}$. In addition, a large number of studies have found that high dietary $\mathrm{Na}$ intake causes an increase in blood pressure that in turn may be associated with increases in CVD and all-cause mortality ${ }^{(7,8)}$. A metaanalysis of prospective studies showed that high salt intake was associated with increased risks of stroke and $\mathrm{CVD}^{(9)}$. However, some studies failed to find such significant association between dietary $\mathrm{Na}$ intake and all-cause or cause-specific mortality ${ }^{(10,11)}$. Another meta-analysis in 2012 showed serious conflicting results among 
observational studies linking $\mathrm{Na}$ intake to CVD events ${ }^{(12)}$. Although Graudal claimed that there is a 'U-shaped' association between dietary $\mathrm{Na}$ intake and CVD mortality ${ }^{(13)}$, a letter by Whelton and Appel rejected this hypothesis ${ }^{(14)}$.

High $\mathrm{Na}$ intake has been strongly associated with different health problems ${ }^{(15,16)}$. However, as mentioned above, there are major controversies over studies investigating the association of $\mathrm{Na}$ intake with all-cause and CVD mortality. In addition, to the best of our knowledge, the exact threshold dose of $\mathrm{Na}$ intake to decrease risk of allcause and CVD events has still not been established. Establishment of this threshold is a health priority and would help to improve available guidelines. Given these reasons, the current systematic review and meta-analysis was done to investigate, for the first time, a dose-response association of dietary $\mathrm{Na}$ intake with all-cause and cardiovascular mortality among prospective studies published up to August 2017.

\section{Methods}

\section{Search strategy}

The present systematic review and meta-analysis of studies was done according to the PRISMA (Preferred Reporting Items for Systematic Reviews and Meta-Analyses) guidelines ${ }^{(17)}$. Eligible studies published up to August 2017 were searched in MEDLINE, EMBASE and Google Scholar databases using combinations of the following keywords: ((sodium chloride[mesh] OR sodium chloride[tiab] OR sodium chloride, dietary[mesh] OR salt [tiab] OR sodium, dietary[mesh] OR sodium[tiab]) AND (cardiovascular diseases[mesh] OR cardiovascular disease* [tiab] OR CVD[tiab] OR all-cause[tiab]) AND (mortality [mesh] OR mortality[tiab] OR death[mesh] OR death[tiab])). The search strategy was limited to studies on human subjects which were published in the English language. We also hand-searched reference lists of the relevant publications to include additional studies.

\section{Eligibility criteria}

Publications were selected according to the following inclusion criteria: population age $\geq 18$ years; categorized $\mathrm{Na}$ intake (at least three categories) for non-linear association as well as continuous intake of $\mathrm{Na}$ for linear association; reported number of participants in each $\mathrm{Na}$ intake category; reported all deaths or/and CVD death numbers in total population and in each $\mathrm{Na}$ intake category; and calculated the hazard ratio (HR) or relative risk (RR) with $95 \%$ CI of all-cause or/and CVD mortality in each category. Exclusion criteria were: randomized clinical trials, crossover, cross-sectional and review studies, letters, comments; non-English language articles; in vitro or animal studies; studies on pregnant women; studies on patients with renal diseases, heart failure, cancers, liver diseases, hypertension, cystic fibrosis and chronic obstructive pulmonary disease; studies in which patients used surgery, drug therapy, transplantation or other physical treatments; and studies that reported only serum $\mathrm{Na}$ concentrations.

\section{Study selection}

Two reviewers independently evaluated titles and abstracts of publications retrieved in the initial search for relevance. Publications which did not meet the eligibility criteria based on study design, population or exposure and outcome were excluded using a screen form. Then, full texts of the candidate relevant articles were retrieved and evaluated again for relevance by the same reviewers. Any disagreements between reviewers were discussed and resolved by the third reviewer (S.S.-B.).

\section{Data extraction}

The following data were extracted from all included publications: study title; study authors; country; year of publication; journal name; study population; participants' sex; follow-up duration; $\mathrm{Na}$ intake categories as well as number of cases; mean $\mathrm{Na}$ intake; mean age; total number of deaths; crude and adjusted HR/RR for all-cause mortality as well as crude and adjusted HR/RR for CVD mortality in each category of $\mathrm{Na}$ intake; and adjustments made.

\section{Statistical analysis}

All statistical analyses were conducted using the statistical software package Stata version 14 . We selected studies in which the HR/RR were reported for all-cause or/and CVD mortality across categories of $\mathrm{Na}$ intake. A dose-dependent meta-analysis using the method proposed by Greenland and Longnecker ${ }^{(18)}$ and Orsini et al. ${ }^{(19)}$ was used to compute the trend from the correlated log HR/RR estimates across $\mathrm{Na}$ intake categories. The midpoint of the $\mathrm{Na}$ intake category was considered as the corresponding HR/ RR estimate. We assumed the open-ended categories to be the same width as the neighbouring categories. A twostage random-effects dose-response meta-analysis was used to investigate a probable non-linear relationship between dietary $\mathrm{Na}$ intake and risk of all-cause and CVD mortality. This was conducted using Na intake modelling and restricted cubic splines with three knots at fixed percentiles of 10, 50 and $90 \%$ of the distribution ${ }^{(20)}$. As described by Orsini et al, a restricted cubic spline model was calculated using generalized least-squares regression accounting for the correlation within each set of published $\mathrm{HR} / \mathrm{RR}^{(19)}$. Then, we combined the study-specific estimates using the restricted maximum likelihood method in a multivariate random-effects meta-analysis ${ }^{(21)}$. A probability value for non-linearity was estimated using null hypothesis testing in which the coefficient of the second spline was considered equal to 0 . A linear dose-response relationship between $100 \mathrm{mg} / \mathrm{d}$ increments in $\mathrm{Na}$ intake 
with CVD and all-cause mortality was estimated using the generalized least-squares trend estimation ${ }^{(18,19,22)}$. We used the two-stage generalized least-squares trend estimation method. To obtain an overall average slope, the study-specific slope lines were estimated and then combined with studies in which the slopes were directly reported ${ }^{(19)}$. Study-specific results were combined using a random-effects model. Studies in which the risk was estimated per any unit increment in $\mathrm{Na}$ intake were also included. Cochran's $Q$ test and the $I^{2}$ statistic were used to assess statistical heterogeneity between the recruited studies $^{(23)} \cdot I^{2}$ values less than $30 \%$ were considered as no or marginal heterogeneity, between 30 and $75 \%$ as mild heterogeneity, and $\geq 75 \%$ as notable between-study heterogeneity. In addition, publication bias was examined using Egger regression ${ }^{(24)}$. Furthermore, the methodological quality of included studies was assessed using the Newcastle-Ottawa Scale adapted for cohort studies. Studies with at least six stars were considered high quality and the rest as low quality.

\section{Results}

\section{Study selection and characteristics of included studies}

Overall, twenty-one publications were included in the current systematic review ${ }^{(11,25-44)}$. The flow diagram of study selection is presented in Fig. 1. In total, 4084 potentially relevant publications were identified through the initial search. After screening based on title and abstract, 195 publications were candidates for more detailed evaluation. Of those, review studies ( $n$ 25), randomized clinical trials ( $n$ 6), non-English language articles ( $n$ 11), studies in which only serum $\mathrm{Na}$ concentration $(n$ 81) was reported and those lacking mortality data ( $n$ 51) were excluded.

All included studies were prospective cohort studies published between 1998 and 2017. Duration of follow-up of the included cohorts was between 1.02 and 20 years. In total, 222189 participants (aged 40.9-74.6 years) were enrolled in the studies. The characteristics of the studies are summarized in Table 1. Among the included studies, nine studies were done in the USA ${ }^{(11,26,28,31,33-36,44)}$, four in Japan ${ }^{(25,29,30,41)}$ and the rest in Canada ${ }^{(32)}$, the Netherlands ${ }^{(27)}$, Belgium ${ }^{(40)}$, China ${ }^{(37)}$, France ${ }^{(38)}$, Finland ${ }^{(39)}$, Brazil $^{(43)}$ and Australia ${ }^{(42)}$. In total, 20270 patients died due to all causes in the studies, while 13806 deaths were due to CVD. Mean Na intake was $3749.03 \mathrm{mg} / \mathrm{d}$ (range: $1035-9400 \mathrm{mg} / \mathrm{d}$ ) among the participants. All studies were done on both sexes. Na intake was assessed using $24 \mathrm{~h}$ urinary $\mathrm{Na}$ excretion in eight studies ${ }^{(26,27,32,33,38-40,42)}$ and using dietary intake assessment in thirteen studies $^{(11,25,28-31,34-37,41,43,44)}$. Among studies in which dietary intake of $\mathrm{Na}$ was assessed, seven studies had used an $\mathrm{FFQ}^{(25,29-31,41,43,44)}$ and five studies used a $24 \mathrm{~h}$ food recall $^{(11,28,34-36)}$. In addition, in one study ${ }^{(37)}$ dietary $\mathrm{Na}$ intake was estimated using a $3 \mathrm{~d}$ food record.

In four studies, participants with the highest consumption of $\mathrm{Na}$ had higher risk of mortality due to all causes than those with the lowest intake ${ }^{(26,32-34)}$. In addition, two studies showed that participants with the highest intake of $\mathrm{Na}$ also had higher cardiovascular mortality compared with those with the lowest intake ${ }^{(25,32)}$. In Nagata et al.'s study, this association was significant only among men ${ }^{(41)}$. In contrast, an inverse association was found for $\mathrm{Na}$ intake with all-cause mortality $^{(36,40)}$ and CVD mortality ${ }^{(11,36,40)}$ when comparing participants in the highest category of $\mathrm{Na}$ intake with those in the lowest. However, differences in all-cause mortality between participants in the highest $v$. those in the lowest category of $\mathrm{Na}$ consumption were not significant in five studies ${ }^{(11,27-29,31)}$. Furthermore, CVD mortality was not also significantly different between participants in the highest $v$. the lowest $\mathrm{Na}$ intake category in five studies ${ }^{(28,30,33,34,44)}$.

In addition, a significant inverse association was found between $\mathrm{Na}$ intake and all-cause $\mathrm{C}^{(35,37,38,42)}$ as well as CVD mortality ${ }^{(37,38,42)}$. In contrast, the association of $\mathrm{Na}$ intake with all-cause ${ }^{(39)}$ and CVD mortality ${ }^{(39,43)}$ was positively significant in some other studies. However, the association of $\mathrm{Na}$ intake with all-cause and CVD mortality ${ }^{(35)}$ was not significant in one study. It should be pointed out that among the included studies, only one study did not adjust findings for potential confounders ${ }^{(42)}$.

\section{Meta-analysis}

After excluding studies without enough required data, nine studies were included in a non-linear dose-response meta-analysis of $\mathrm{Na}$ intake and CVD mortality $^{(11,25,28,30,32,33,40,41,44)}$ and eight studies in a non-linear meta-analysis of $\mathrm{Na}$ intake and all-cause mortality $^{(11,26,28,29,31-33,40)}$. We found a significant non-linear association $\left(P_{\text {non-linearity }}<0.001\right)$ between $\mathrm{Na}$ intake and the risk of CVD mortality among studies in which urinary excretion of $\mathrm{Na}$ was examined, with a relatively steep slope at $\mathrm{Na}$ intakes higher than $2400 \mathrm{mg} / \mathrm{d}$ (Fig. 2(b)). However, the association was not significant in those studies which examined dietary intake of $\mathrm{Na}(P=0 \cdot 61$; Fig. 2(a)). In contrast, the non-linear association of $\mathrm{Na}$ intake with all-cause mortality was not significant in studies assessing both dietary intake $(P=0 \cdot 85$; Fig. 3(a)) and urinary excretion ( $P=0.79$; Fig. 3(b)). When we combined data from studies using dietary intake and those assessing urinary excretion of $\mathrm{Na}$, a significant association was found between $\mathrm{Na}$ intake and CVD mortality (Fig. 4). However, the association of $\mathrm{Na}$ intake with all-cause mortality was still not significant (Fig. 5).

In addition, the linear trend of $\mathrm{Na}$ intake with $\operatorname{CVD}^{(11,25,28,30,32,33,35,37-42,44)}$ and all-cause mortality $(11,26,28,29,31-33,35,37-40,42)$ was analysed. No 


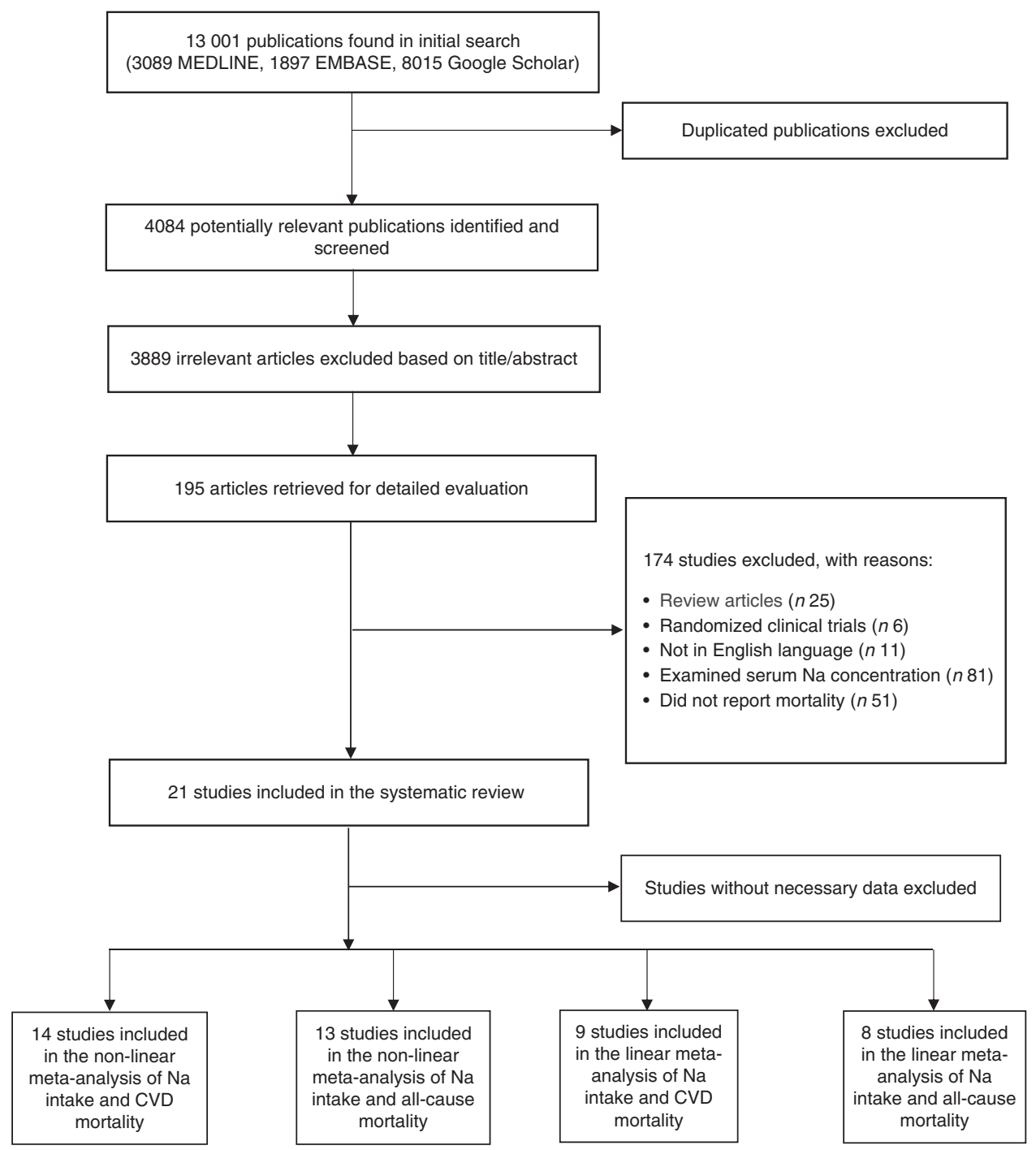

Fig. 1 Flow diagram of study selection for the present systematic review and meta-analysis of prospective studies on the association of dietary sodium intake with all-cause and cardiovascular mortality

significant association was found between $100 \mathrm{mg} / \mathrm{d}$ increment in $\mathrm{Na}$ intake and CVD mortality in the current study (effect size $=1.01 ; 95 \%$ CI $0.97,1 \cdot 05 ; I^{2}=98.4 \%$; Fig. 6). Due to substantial heterogeneity between the included studies, we conducted a subgroup analysis based on publication country (USA/Japan/other countries), follow-up duration ( $<10$ years $\geq 10$ years), exposure assessment method (dietary intake assessment/urinary $\mathrm{Na}$ excretion), study sample size ( $<5000$ persons/ $\geq 5000$ persons), study quality (low/high) and daily $\mathrm{Na}$ intake (<3000 mg/ $\geq 3000 \mathrm{mg}$; Fig. 7(a)-(f)). Among the subgroup analyses, between-study heterogeneity disappeared only among studies conducted in the USA (effect size $=0.99 ; 95$ $\%$ CI $0.99,1.00 ; I^{2}=20.0 \%$ ). Sensitivity analysis showed that neither an individual study nor a group of studies had a significant influence on our results (data not shown).

Furthermore, a $100 \mathrm{mg} / \mathrm{d}$ increment in $\mathrm{Na}$ intake was not significantly associated with all-cause mortality in the current study (effect size $=1 \cdot 01 ; 95 \%$ CI 1.00, 1.02; $I^{2}=89.2 \%$; Fig. 8). The subgroup analysis was done based on publication country (USA/non-USA), follow-up duration ( $<10$ years/ $\geq 10$ years), exposure assessment method (dietary intake assessment/urinary $\mathrm{Na}$ excretion), study sample size (<5000 persons/ $\geq 5000$ persons), study quality (low/high) and daily intake of $\mathrm{Na}$ $(<3000 \mathrm{mg} / \geq 3000 \mathrm{mg} ; \quad$ see online supplementary material, Supplemental Fig. 1(a)-(f)); results showed that none of them was the potential source of heterogeneity. However, the most reduction in heterogeneity occurred when we did the reanalysis based on exposure assessment method among the studies which had used dietary intake measures (effect size $=1.00 ; 95 \%$ CI 1.00, 1.01; $I^{2}=65.8 \%$ ). In addition, sensitivity analysis showed that neither an individual study nor a group of studies had a considerable influence on the final finding (data not shown). 
Table 1 Continued

\begin{tabular}{|c|c|c|c|c|c|c|c|c|c|c|c|c|c|c|c|}
\hline Study & Country & $\begin{array}{l}\text { Age (years), } \\
\text { range or mean }\end{array}$ & $\begin{array}{c}\text { Mean Na } \\
\text { intake } \\
(\mathrm{mg} / \mathrm{d})\end{array}$ & Sex & $\begin{array}{l}\text { Sample } \\
\text { size }\end{array}$ & $\begin{array}{l}\text { No. of all- } \\
\text { cause deaths }\end{array}$ & $\begin{array}{l}\text { No. of CVD } \\
\text { deaths }\end{array}$ & $\begin{array}{c}\text { Duration } \\
\text { follow-up } \\
\text { (years) }\end{array}$ & $\begin{array}{l}\text { Exposure } \\
\text { assessment }\end{array}$ & $\begin{array}{l}\text { Na intake } \\
\text { categories }\end{array}$ & Outcome & OR or RR & $95 \% \mathrm{Cl}$ & Adjustments ${ }^{*}$ & $\begin{array}{l}\text { Study } \\
\text { quality }\end{array}$ \\
\hline $\begin{array}{l}\text { Geleijnse et al. } \\
(2007)^{(27)}\end{array}$ & Netherlands & 69.2 & 2691 & $\mathrm{~F} / \mathrm{M}$ & 1448 & 420 & - & 5 & $\begin{array}{l}24 \mathrm{~h} \text { urinary } \\
\mathrm{Na} \text { excretion }\end{array}$ & Q1, Q2, Q3, Q4‡ & $\begin{array}{l}\text { All-cause } \\
\text { mortality }\end{array}$ & All-cause: 0.98 & $0.54,1.78$ & $\begin{array}{c}1,2,3,4,6,8,9,15 \\
27,42,49,67,74\end{array}$ & 5 \\
\hline $\begin{array}{l}\text { Cohen et al. } \\
(2006)^{(36)}\end{array}$ & USA & 48 & 2718 & $\mathrm{~F} / \mathrm{M}$ & 7154 & 1343 & 541 & 13.7 & $\begin{array}{l}\text { Dietary intake } \\
(24 \mathrm{~h} \text { recall) }\end{array}$ & $\begin{array}{c}<2300, \geq 2300 \\
\mathrm{mg} / \mathrm{d}\end{array}$ & $\begin{array}{l}\text { All-cause/ } \\
\text { CVD mortality }\end{array}$ & $\begin{array}{l}\text { All-cause: } 0.83 \\
\text { CVD: } 0.71\end{array}$ & $\begin{array}{l}0.73,0.94 \\
0.57,0.88\end{array}$ & 1,2 & 5 \\
\hline $\begin{array}{l}\text { Nagata et al. } \\
\quad(2004)^{(41)}\end{array}$ & Japan & 54 & 5659 & M & 13355 & - & 137 & 7 & $\begin{array}{l}24 \mathrm{~h} \text { urinary } \\
\text { Na excretion }\end{array}$ & $\begin{array}{l}\text { Low, moderate, } \\
\text { high }\end{array}$ & CVD mortality & CVD: 2.33 & $1.23,4.45$ & $\begin{array}{r}1,6,7,8,9,15,23 \\
27,42,48,71,75,76\end{array}$ & 5 \\
\hline $\begin{array}{l}\text { Nagata et al. } \\
\quad(2004)^{(41)}\end{array}$ & Japan & $55 \cdot 2$ & 5210 & $\mathrm{~F}$ & 15724 & - & 132 & 7 & $\begin{array}{l}24 \mathrm{~h} \text { urinary } \\
\mathrm{Na} \text { excretion }\end{array}$ & $\begin{array}{l}\text { Low, moderate, } \\
\text { high }\end{array}$ & CVD mortality & CVD: 1.7 & $0.96,3.02$ & $\begin{array}{l}1,6,7,8,9,15,23 \\
27,42,48,71,75,76\end{array}$ & 5 \\
\hline $\begin{array}{l}\text { Tuomilehto et al. } \\
(2001)^{(39)}\end{array}$ & Finland & 45.5 & 4140 & $\mathrm{~F} / \mathrm{M}$ & 2436 & 180 & 87 & NR & $\begin{array}{l}24 \mathrm{~h} \text { urinary } \\
\mathrm{Na} \text { excretion }\end{array}$ & $-t$ & $\begin{array}{l}\text { All-cause/ } \\
\text { CVD mortality }\end{array}$ & $\begin{array}{l}\text { All-cause: } 1.22 \\
\text { CVD: } 1.36\end{array}$ & $\begin{array}{l}1.02,1.47 \\
1.05,1.76\end{array}$ & $\begin{array}{c}1,2,9,15,16,34 \\
38,77\end{array}$ & 8 \\
\hline He et al. $(1999)^{(28)}$ & USA & $48 \cdot 2$ & 1952 & $\mathrm{~F} / \mathrm{M}$ & 6797 & 1676 & 566 & 19 & $\begin{array}{l}\text { Dietary intake } \\
\text { ( } 24 \mathrm{~h} \text { recall) }\end{array}$ & Q1, Q2, Q3, Q4 & $\begin{array}{l}\text { All-cause/ } \\
\text { CVD mortality }\end{array}$ & $\begin{array}{l}\text { All-cause: } 1.02 \\
\text { CVD: } 1.18\end{array}$ & $\begin{array}{l}0.88,1.19 \\
0.92,1.51\end{array}$ & $\begin{array}{c}1,2,6,8,9,14,15 \\
16,24,27,34,42,74\end{array}$ & 5 \\
\hline $\begin{array}{l}\text { Alderman et al. } \\
(1998)^{(35)}\end{array}$ & USA & $49 \cdot 2$ & 2023 & $\mathrm{~F} / \mathrm{M}$ & 11346 & 3923 & 1970 & 20 & $\begin{array}{l}\text { Dietary intake } \\
(24 \mathrm{~h} \text { recall) }\end{array}$ & $-\dagger$ & $\begin{array}{l}\text { All-cause/ } \\
\text { CVD mortality }\end{array}$ & $\begin{array}{l}\text { All-cause: } 0.88 \\
\text { CVD: } 0.89\end{array}$ & $\begin{array}{l}0.80,0.96 \\
0.77,1.02\end{array}$ & $N R$ & 3 \\
\hline
\end{tabular}

\section{F, female; M, male; NR, not reported.}

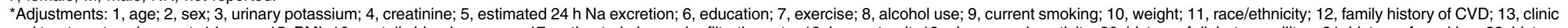

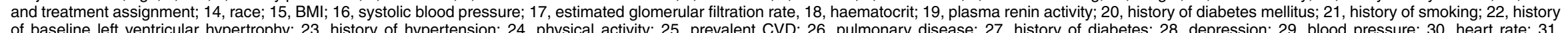

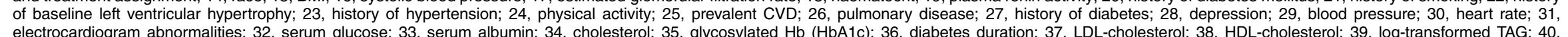

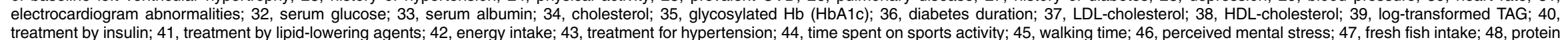
treatment by insulin; 41 , treatment by lipid-lowering agents; 42 , energy intake; 43 , treatment for hypertension; 44, time spent on sports activity; 45 , walking time; 46 , perceived mental stress; 47 , fresh fish intake; 48 , protein intake; 49 , saturated fat intake; 50 , carbohydrate intake; 51 , hypercholesterolaemia; 52 , previous cardiac disease; 53 , total fat intake; 54 , myocardial infarction; 55 , left ventricular end-diastolic volume; 56 , C-reactive protein; systolic blood pressure from baseline to last follow-up; 63 , study population; 64 , average mean arterial pressure; 65 , Hb; 66 , phosphate intake; 67 , calcium intake; 68 , Kt/V; 69 , added table salt; 70, history of cancer; 71 , dietary potassium; 72 , menopause; 73 , hormone replacement therapy; 74 , diuretic use; 75 , marital status; 76 , intake of vitamin $\mathrm{E} ; 77$, study year.

†Reported risk of mortality for continuous intake of $\mathrm{Na}$.

†Quartiles.

§Quintiles. 

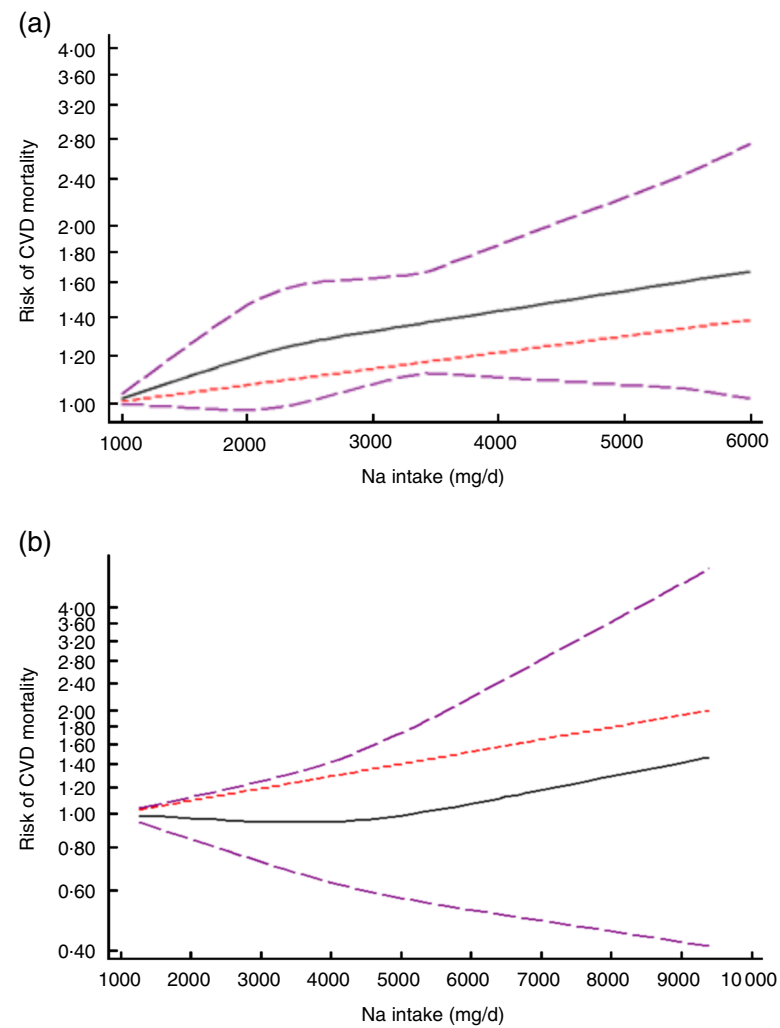

Fig. 2 (colour online) The non-linear association meta-analysis between adjusted hazard ratios of CVD mortality and sodium intake among studies using (a) dietary intake assessment and (b) urinary sodium excretion. Sodium intake was modelled with restricted cubic splines in a multivariate random-effects doseresponse model (------, linear model; - , spline model; ----, $95 \% \mathrm{Cl})$; the vertical axis is on a log scale

\section{Discussion}

In the current study, we found that there was no significant association of $100 \mathrm{mg} / \mathrm{d}$ increment in $\mathrm{Na}$ intake with CVD and all-cause mortality. High levels of heterogeneity were found between the studies. The country where the study was conducted and the method for the assessment of $\mathrm{Na}$ were the potential sources of heterogeneity.

We also found a non-linear direct association between urinary excretion of $\mathrm{Na}$ and the risk of CVD mortality. This association was more considerable at $\mathrm{Na}$ intakes higher than $2400 \mathrm{mg} / \mathrm{d}$. In addition, we failed to find a non-linear association between $\mathrm{Na}$ intake and all-cause mortality.

Our meta-analysis showed a non-linear direct association between $\mathrm{Na}$ urinary excretion and CVD mortality, which was more considerable at $\mathrm{Na}$ intakes higher than $2400 \mathrm{mg} / \mathrm{d}$. This finding is in line with the American Heart Association guidelines, which recommend consumption of no more than $2400 \mathrm{mg}$ of $\mathrm{Na}$ daily ${ }^{(45)}$. However, our included studies did not have sufficient data for extreme low and high intakes of $\mathrm{Na}$. Mean $\mathrm{Na}$ intake of participants in the studies was between 3000 and $5000 \mathrm{mg} / \mathrm{d}$. Therefore, more studies are needed to find an association between extreme low or high $\mathrm{Na}$ intakes and mortality. (a)

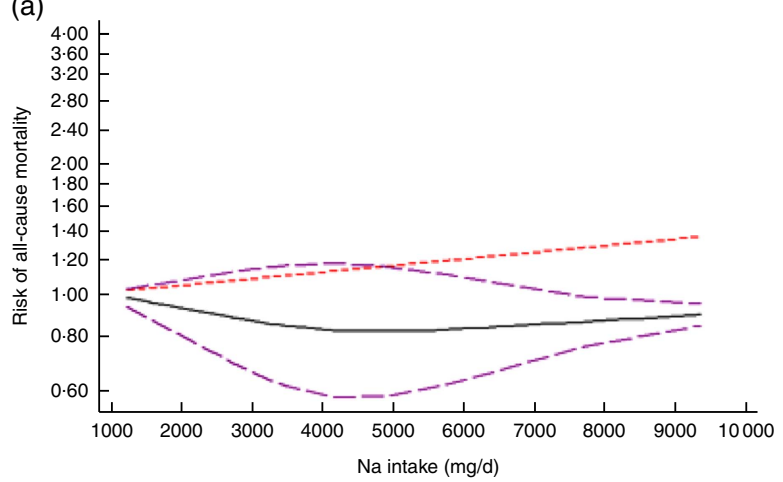

(b)

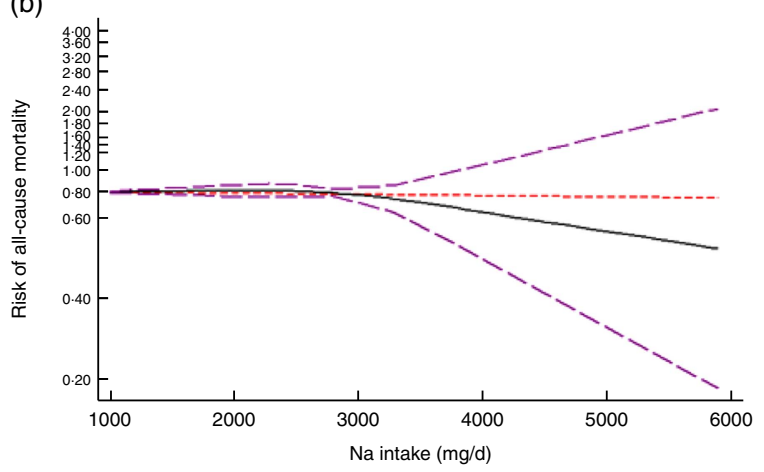

Fig. 3 (colour online) The non-linear association meta-analysis between adjusted hazard ratios of all-cause mortality and sodium intake among studies using (a) dietary intake assessment and (b) urinary sodium excretion. Sodium intake was modelled with restricted cubic splines in a multivariate random-effects dose-response model (------, linear model; _ , spline model; ---, $95 \% \mathrm{Cl}$ ); the vertical axis is on a $\log$ scale

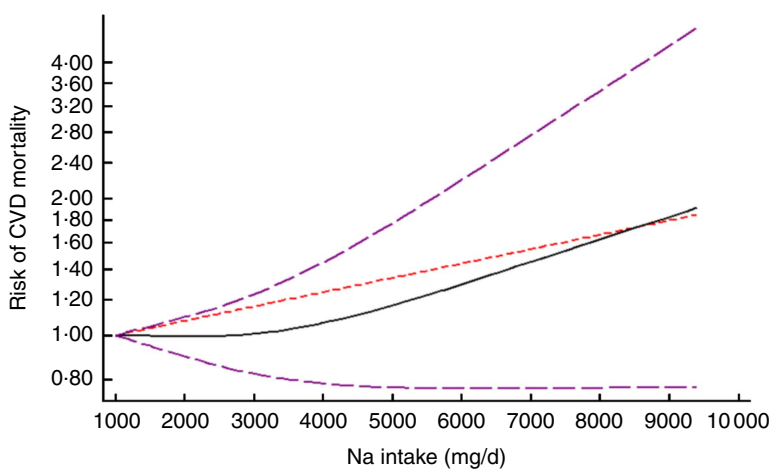

Fig. 4 (colour online) The non-linear association meta-analysis between adjusted hazard ratios of CVD mortality and sodium intake. Sodium intake was modelled with restricted cubic splines in a multivariate random-effects dose-response model (-----, linear model; __ spline model; ----, $95 \% \mathrm{Cl}$ ); the vertical axis is on a log scale

Findings of previous meta-analyses in this area are controversial. In Alderman and Cohen's meta-analysis, although there was an inverse association between $\mathrm{Na}$ intake and CVD mortality among individuals who had consumed less than $4500 \mathrm{mg} \mathrm{Na} / \mathrm{d}$, the association was direct among those with a higher $\mathrm{Na}$ intake. Moreover, a 'J-shaped' association was 
found between $\mathrm{Na}$ intake and CVD mortality in two observational studies included in that meta-analysis ${ }^{(12)}$. In addition, Graudal claimed that there is a 'U-shaped' association between dietary $\mathrm{Na}$ intake and CVD mortality ${ }^{(13)}$. Furthermore, another study reported a significant association between $\mathrm{Na}$ intake and risk of $\mathrm{CVD}^{(9)}$. However, the significance was achieved only by the arbitrary exclusion of the Alderman et al. study with sufficient numbers at the low end.

We could not find a significant association between $\mathrm{Na}$ intake and CVD mortality among studies in which a dietary assessment tool was used to estimate participants' $\mathrm{Na}$ intake. But the association was significant among studies

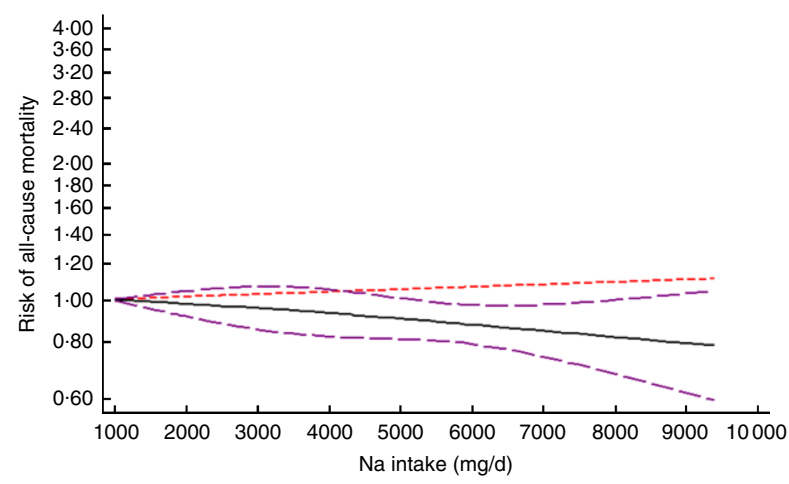

Fig. 5 (colour online) The non-linear association meta-analysis between adjusted hazard ratios of all-cause mortality and sodium intake. Sodium intake was modelled with restricted cubic splines in a multivariate random-effects dose-response model (------, linear model; __, spline model; ---, $95 \% \mathrm{Cl}$ ); the vertical axis is on a log scale which had used $24 \mathrm{~h}$ urinary $\mathrm{Na}$ excretion. It should be noted that dietary intake assessment may not reflect actual dietary intakes of participants such that intake of some minerals including $\mathrm{Na}$ is frequently underestimated while urinary Na may provide adequately acceptable population estimates $^{(46)}$.

Additionally, there was no association between $\mathrm{Na}$ intake and all-cause mortality in the current meta-analysis. This finding was also observed even after the subgroup analyses based on the method of $\mathrm{Na}$ intake estimation, including $24 \mathrm{~h}$ urinary $\mathrm{Na}$ excretion and dietary intake assessment methods. To the best of our knowledge, there is no systematic review or meta-analysis available investigating the association of dietary $\mathrm{Na}$ intake with all-cause mortality among cohorts. However, in line with our findings, a huge body of evidence has failed to find any significant association between dietary Na intake and all-cause mortality ${ }^{(11,27-29,31)}$. Moreover, other meta-analysis studies have also shown inconsistent findings, such that a metaanalysis in 2013 could not find a significant association between lower dietary Na intake and all-cause mortality ${ }^{(47)}$, whereas another meta-analysis in 2014 found a significant positive association between higher than normal $\mathrm{Na}$ intake and all-cause mortality as well as CVD events ${ }^{(48)}$. However, neither of those studies performed a dose-response metaanalysis; furthermore, few studies were included for the mortality outcome in their analyses. Higher consumption of $\mathrm{Na}$ has been linked to a higher risk of all-cause mortality in some other studies ${ }^{(26,32-34)}$. Although these studies found a significant association, the observed increase in the risk of all-cause mortality was often small and it was not adjusted

\begin{tabular}{|c|c|c|}
\hline Study & ES $(95 \% \mathrm{Cl})$ & Weight (\%) \\
\hline Alderman et al. $(1998)^{(35)}$ & $0.85(0.70,1.03)$ & $2 \cdot 87$ \\
\hline Cohen et al. $(2008)^{(11)}$ & $1.01(0.95,1.07)$ & $9 \cdot 19$ \\
\hline Dong et al. $(2010)^{(37)}$ & $0.11(0.03,0.44)$ & 0.07 \\
\hline O'Donnell et al. (2011) & $1.02(1.01,1.03)$ & $12 \cdot 14$ \\
\hline Ekinci et al. $(2011)^{(42)}$ & $0.37(0.15,0.90)$ & 0.17 \\
\hline Gardener et al. $(2012)^{(44)}$ & $1.04(0.94,1.15)$ & $6 \cdot 31$ \\
\hline He et al. $(1999)^{(28)}$ & $1.03(0.96,1.11)$ & $8 \cdot 21$ \\
\hline Ikehara et al. (2012) ${ }^{(30)}$ & $1.00(0.96,1.04)$ & $10 \cdot 61$ \\
\hline Nagata et al. $(2004)^{(41)}$ & $1 \cdot 11(1 \cdot 02,1 \cdot 20)$ & 7.59 \\
\hline Nagata et al. $(2004)^{(41)}$ & $1.07(0.98,1.16)$ & $7 \cdot 38$ \\
\hline Saulnier et al. $(2017)^{(38)}$ & $0.47(0.32,0.69)$ & 0.87 \\
\hline Singer et al. $(2015)^{(33)}$ & $0.99(0.98,1.00)$ & $12 \cdot 14$ \\
\hline Stolarz-Skrzypek et al. $(2011)^{(40)}$ & $0.92(0.92,0.92)$ & $12 \cdot 14$ \\
\hline Tuomilehto et al. (2001) & $2.02(1.11,3.67)$ & 0.36 \\
\hline Umesawa et al. (2008) & $1 \cdot 11(1 \cdot 06,1 \cdot 17)$ & 9.95 \\
\hline Overall $\left(I^{2}=98.4 \%, P=0.000\right)$ & $1.01(0.97,1.05)$ & $100 \cdot 00$ \\
\hline \multicolumn{3}{|c|}{ NOTE: Weights are from random-effects analysis } \\
\hline \multirow[t]{2}{*}{0.0275} & $36 \cdot 4$ & \\
\hline & & \\
\hline
\end{tabular}

Fig. 6 (colour online) Forest plot for the linear trend meta-analysis between $100 \mathrm{mg} / \mathrm{d}$ increment in sodium intake and CVD mortality. The effect size (ES) and $95 \% \mathrm{Cl}$ are represented by the black diamond and horizontal line, respectively; the study weight diamond is proportional to the inverse of the variance of the ES. The centre of the blue open diamond and the vertical dashed red line represent the pooled ES, the width of the open diamond represents the pooled $95 \% \mathrm{Cl}$ and the vertical black line at $\mathrm{ES}=1$ represents the null effect 
(a)

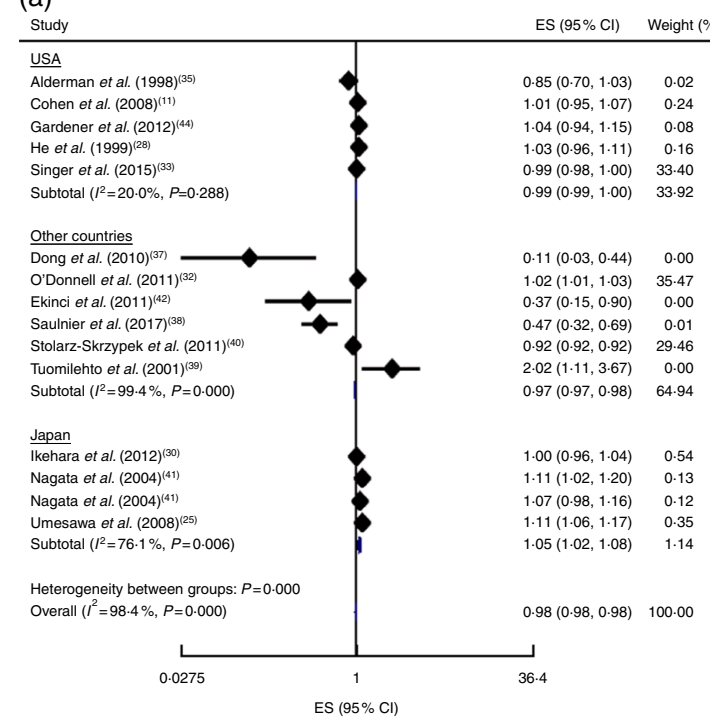

(d)

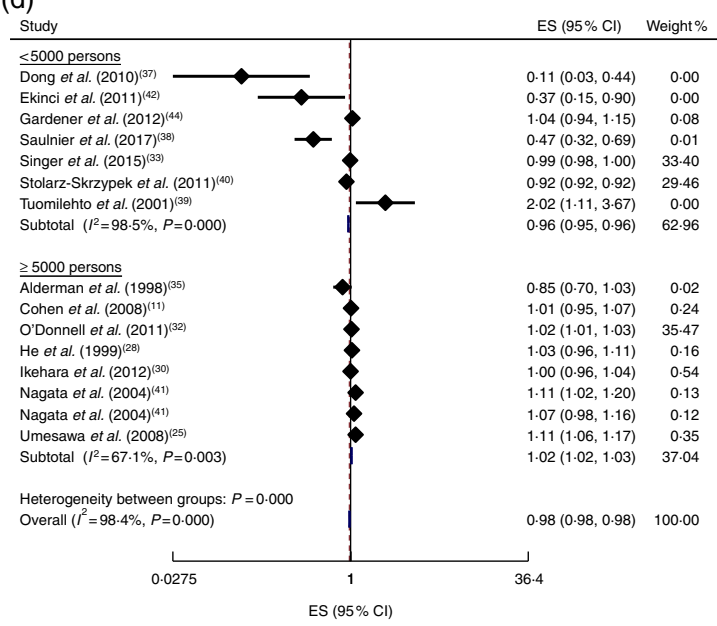

(b)

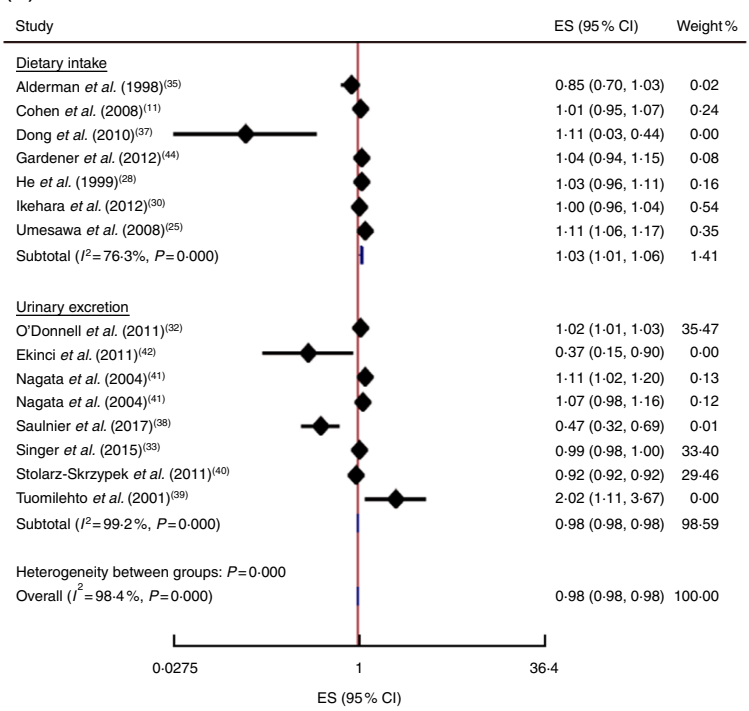

(e)

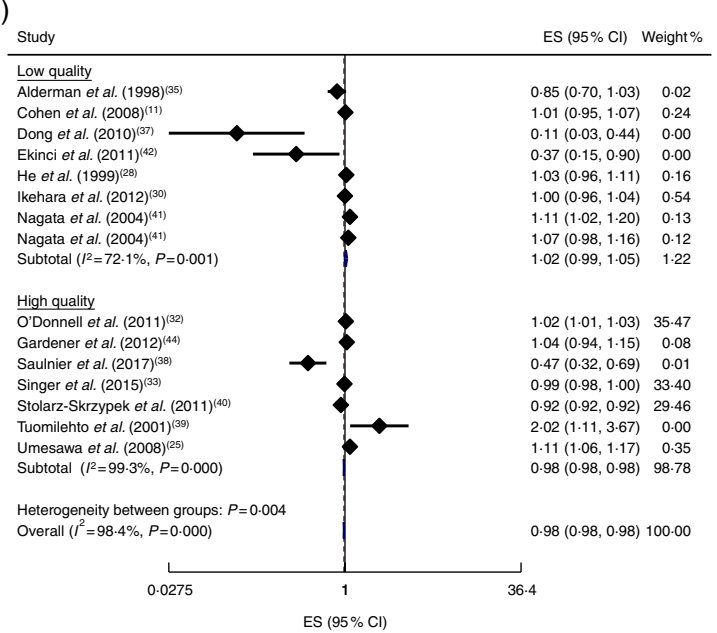

(c)
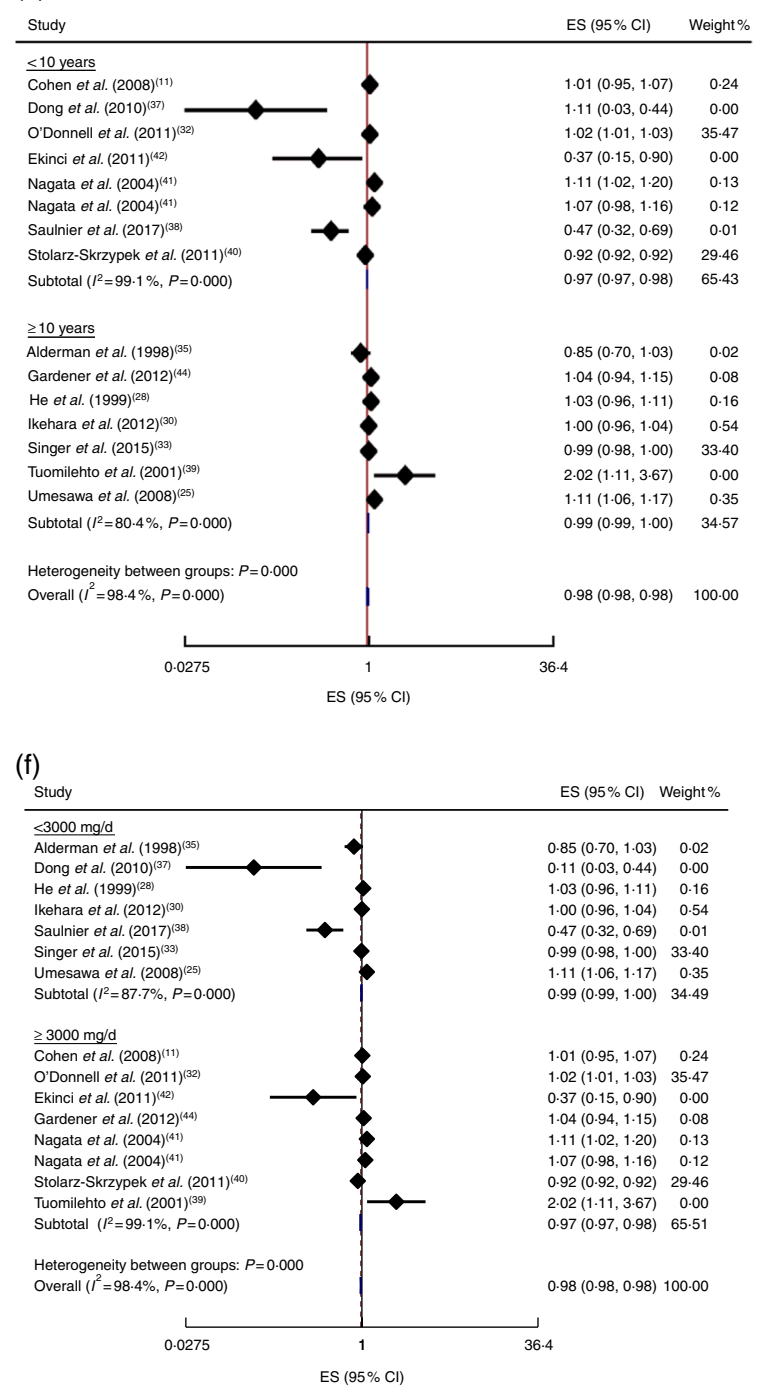

Fig. 7 (colour online) Forest plots for subgroup analysis of the linear trend meta-analysis between $100 \mathrm{mg} / \mathrm{d}$ increment in sodium intake and CVD mortality by (a) country, (b) exposure

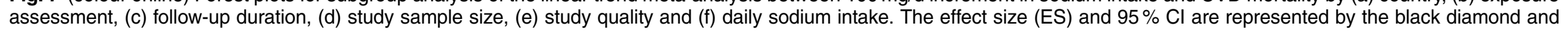

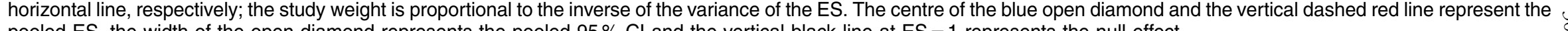
pooled ES, the width of the open diamond represents the pooled $95 \% \mathrm{Cl}$ and the vertical black line at $\mathrm{ES}=1$ represents the null effect 


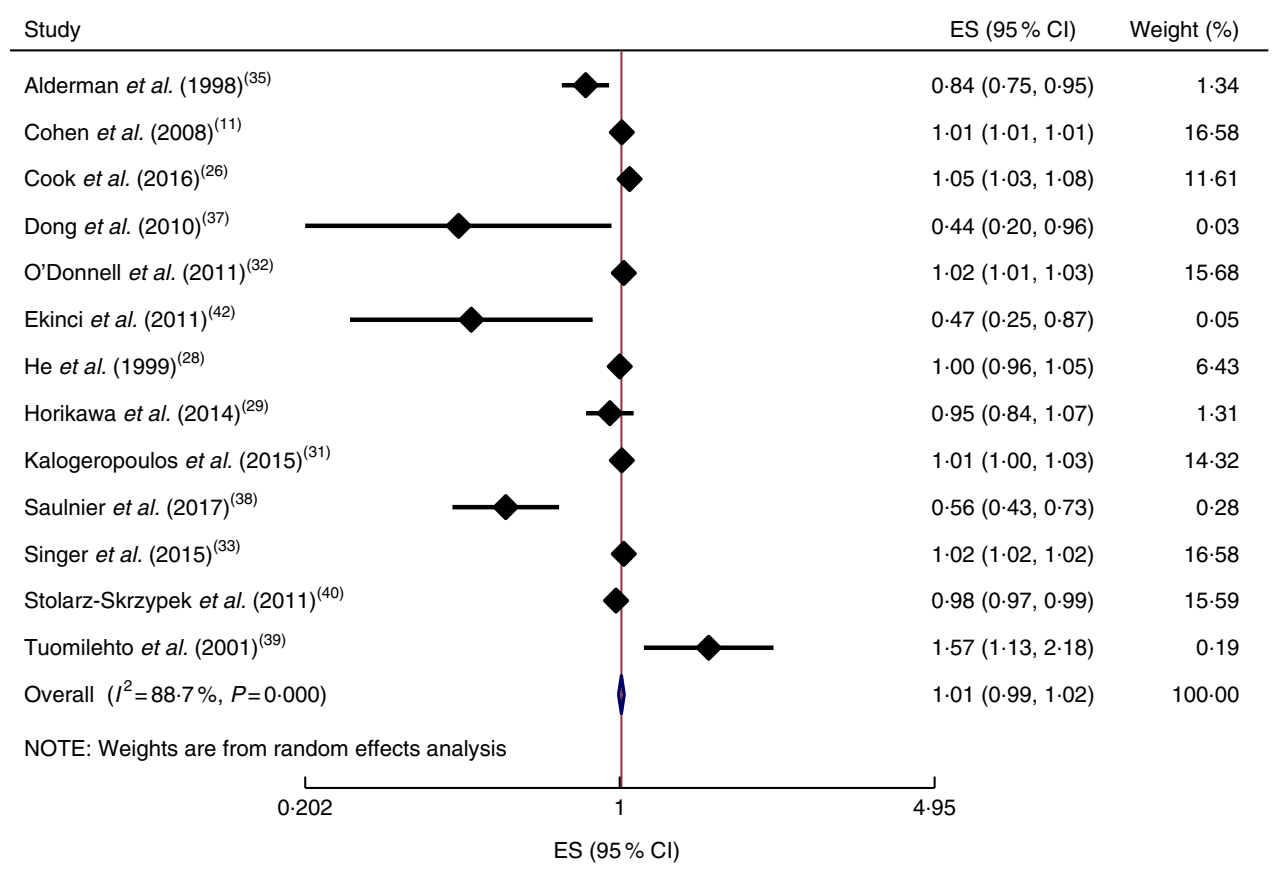

Fig. 8 (colour online) Forest plot for the linear trend meta-analysis between $100 \mathrm{mg} / \mathrm{d}$ increment in sodium intake and all-cause mortality. The effect size (ES) and $95 \% \mathrm{Cl}$ are represented by the black diamond and horizontal line, respectively; the study weight is proportional to the inverse of the variance of the ES. The centre of the blue open diamond and the vertical dashed red line represent the pooled ES, the width of the open diamond represents the pooled $95 \% \mathrm{Cl}$ and the vertical black line at ES $=1$ represents the null effect

for some important confounders, including dietary intakes of participants. In contrast to these findings, two other studies have shown an inverse association between $\mathrm{Na}$ intake and all-cause mortality ${ }^{(36,40)}$. However, mean $\mathrm{Na}$ intake in these studies was frequently lower than that observed among the rest of the studies.

$\mathrm{Na}$ concentration in serum regulates osmotic pressure and thus blood pressure ${ }^{(49)}$. The increase in $\mathrm{Na}$ concentration due to consumption of high-salt diets disturbs normal function of blood vessel endothelium and elevates heart burden ${ }^{(50)}$. Accordingly, high Na consumption could be assumed as a risk factor for CVD mortality.

The present study is the first dose-response metaanalysis on the association of dietary $\mathrm{Na}$ intake with CVD and all-cause mortality among cohort studies. Including cohort studies with larger sample sizes and long-term follow-ups may result in a firmer conclusion. However, some limitations should be noted. The most of the cohorts included were done in the USA, where the population has specific dietary behaviours different from many other countries. This is important to consider because we know that the study country was a source of heterogeneity in our linear meta-analysis on the association between $\mathrm{Na}$ intake and CVD mortality. High between-study heterogeneity is another limitation of the current meta-analysis. Furthermore, considering different confounders may also explain different findings of the included studies. In addition, dietary intake of $\mathrm{Na}$ was estimated using an FFQ or a $24 \mathrm{~h}$ food recall in most of the included studies. Due to the low number of studies using each of these two methods, we could not separately analyse data for them. Moreover, misclassification of participants may occur when using an FFQ, and the latter also might not reflect sufficiently longterm dietary intakes ${ }^{(51)}$. Besides, a unique $24 \mathrm{~h}$ food recall cannot reflect long-term dietary intakes of participants ${ }^{(52)}$.

\section{Conclusion}

In conclusion, the current dose-response meta-analysis showed a direct association between urinary excretion of $\mathrm{Na}$ and CVD mortality which was more considerable at $\mathrm{Na}$ intakes higher than $2400 \mathrm{mg} / \mathrm{d}$. However, we failed to find a significant association between $\mathrm{Na}$ intake and all-cause mortality. Further studies, especially long-term prospective cohorts in different populations, are required to confirm these findings.

\section{Acknowledgements}

Financial support: This research received no specific grant from any funding agency in the public, commercial or notfor-profit sectors. Conflict of interest: The authors have no conflicts of interest to declare. Authorship: A.M. and K.D. designed the study. A.M. and S.S.-B. analysed and interpreted the data. A.M. wrote the manuscript. S.S.-B. and K.D. revised the manuscript. Ethics of buman subject participation: Not applicable; this study had no human or animal intervention. 


\section{Supplementary material}

To view supplementary material for this article, please visit https://doi.org/10.1017/S1368980018002112

\section{References}

1. Dugani S \& Gaziano TA (2016) 25 by 25: achieving global reduction in cardiovascular mortality. Curr Cardiol Rep 18, 10 .

2. Roth GA, Forouzanfar MH, Moran AE et al. (2015) Demographic and epidemiologic drivers of global cardiovascular mortality. N Engl J Med 372, 1333-1341.

3. Bloom D, Cafiero E, Jané-Llopis E et al. (2012) The Global Economic Burden of Noncommunicable Diseases. PGDA Working Paper from the Program on the Global Demography of Aging. https://econpapers.repec.org/paper/ gdmwpaper/8712.htm (accessed October 2017).

4. Kim LG, Adamson J \& Ebrahim S (2013) Influence of lifestyle choices on locomotor disability, arthritis and cardiovascular disease in older women: prospective cohort study. Age Ageing 42, 696-701.

5. Sotos-Prieto M, Bhupathiraju SN, Mattei J et al. (2017) Association of changes in diet quality with total and causespecific mortality. N Engl J Med 377, 143-153.

6. Mirmiran P, Bahadoran Z, Vakili AZ et al. (2016) Western dietary pattern increases risk of cardiovascular disease in Iranian adults: a prospective population-based study. Appl Physiol Nutr Metab 42, 326-332.

7. He J \& Whelton PK (2002) Salt intake, hypertension and risk of cardiovascular disease: an important public health challenge (Commentary). Int J Epidemiol 31, 327-331.

8. Prospective Studies Collaboration (2002) Age-specific relevance of usual blood pressure to vascular mortality: a metaanalysis of individual data for one million adults in 61 prospective studies. Lancet 360, 1903-1913.

9. Strazzullo P, D'Elia L, Kandala N-B et al. (2009) Salt intake, stroke, and cardiovascular disease: meta-analysis of prospective studies. BMJ 339, b4567.

10. Perry I \& Beevers D (1992) Salt intake and stroke: a possible direct effect. J Hum Hypertens 6, 23-25.

11. Cohen HW, Hailpern SM \& Alderman MH (2008) Sodium intake and mortality follow-up in the Third National Health and Nutrition Examination Survey (NHANES III). J Gen Intern Med 23, 1297-1302.

12. Alderman MH \& Cohen HW (2012) Dietary sodium intake and cardiovascular mortality: controversy resolved? $\mathrm{Am} \mathrm{J}$ Hypertens 25, 727-734.

13. Graudal N (2014) The data show a U-shaped association of sodium intake with cardiovascular disease and mortality. Am J Hypertens 28, 424-425.

14. Whelton PK \& Appel LJ (2014) Response to 'The data show a U-shaped association of sodium intake with cardiovascular disease and mortality'. Am J Hypertens 28, 426-427.

15. Steffen LM (2014) Lower levels of sodium intake and reduced cardiovascular risk. Circulation 129, 956-957.

16. Yakoob MY, Micha R, Khatibzadeh S et al. (2016) Impact of dietary and metabolic risk factors on cardiovascular and diabetes mortality in South Asia: analysis from the 2010 Global Burden of Disease Study. Am J Public Health 106, 2113-2125.

17. Moher D, Liberati A, Tetzlaff J et al. (2009) Preferred reporting items for systematic reviews and meta-analyses: the PRISMA statement. Ann Intern Med 151, 264-269.

18. Greenland S \& Longnecker MP (1992) Methods for trend estimation from summarized dose-response data, with applications to meta-analysis. Am J Epidemiol 135, 1301-1309.
19. Orsini N, Bellocco R \& Greenland S (2006) Generalized least squares for trend estimation of summarized doseresponse data. Stata $J \mathbf{6}, 40-57$.

20. Harre FE, Lee KL \& Pollock BG (1988) Regression models in clinical studies: determining relationships between predictors and response. J Natl Cancer Inst $\mathbf{8 0}$, $1198-1202$.

21. Jackson D, White IR \& Thompson SG (2010) Extending DerSimonian and Laird's methodology to perform multivariate random effects meta-analyses. Stat Med 29, 1282-1297.

22. Berlin JA, Longnecker MP \& Greenland S (1993) Metaanalysis of epidemiologic dose-response data. Epidemiology $\mathbf{4}, 218-228$.

23. Higgins JP \& Thompson SG (2002) Quantifying heterogeneity in a meta-analysis. Stat Med 21, 1539-1558.

24. Egger M, Smith GD, Schneider M et al. (1997) Bias in metaanalysis detected by a simple, graphical test. BMJ 315, 629-634.

25. Umesawa M, Iso H, Date C et al. (2008) Relations between dietary sodium and potassium intakes and mortality from cardiovascular disease: the Japan Collaborative Cohort Study for Evaluation of Cancer Risks. Am J Clin Nutr 88, 195-202.

26. Cook NR, Appel LJ \& Whelton PK (2016) Sodium intake and all-cause mortality over 20 years in the trials of hypertension prevention. J Am Coll Cardiol 68, 1609-1617.

27. Geleijnse JM, Witteman JC, Stijnen T et al. (2007) Sodium and potassium intake and risk of cardiovascular events and all-cause mortality: the Rotterdam study. Eur J Epidemiol 22, $763-770$.

28. He J, Ogden LG, Vupputuri S et al. (1999) Dietary sodium intake and subsequent risk of cardiovascular disease in overweight adults. JAMA 282, 2027-2034.

29. Horikawa C, Yoshimura Y, Kamada C et al. (2014) Dietary sodium intake and incidence of diabetes complications in Japanese patients with type 2 diabetes: analysis of the Japan Diabetes Complications Study (JDCS). J Clin Endocrinol Metab 99, 3635-3643.

30. Ikehara S, Iso H, Date C et al. (2012) Salt preference and mortality from stroke and coronary heart disease for Japanese men and women: the JACC study. Prev Med 54, 32-37.

31. Kalogeropoulos AP, Georgiopoulou VV, Murphy RA et al. (2015) Dietary sodium content, mortality, and risk for cardiovascular events in older adults: the Health, Aging, and Body Composition (Health ABC) Study. JAMA Intern Med 175, 410-419.

32. O'Donnell MJ, Yusuf S, Mente A et al. (2011) Urinary sodium and potassium excretion and risk of cardiovascular events. JAMA 306, 2229-2238.

33. Singer P, Cohen H \& Alderman M (2015) Assessing the associations of sodium intake with long-term all-cause and cardiovascular mortality in a hypertensive cohort. Am J Hypertens 28, 335-342.

34. Yang Q, Liu T, Kuklina EV et al. (2011) Sodium and potassium intake and mortality among US adults: prospective data from the Third National Health and Nutrition Examination Survey. Arch Intern Med 171, 1183-1191.

35. Alderman MH, Cohen H \& Madhavan S (1998) Dietary sodium intake and mortality: the National Health and Nutrition Examination Survey (NHANES I). Lancet 351, 781-785.

36. Cohen HW, Hailpern SM, Fang J et al. (2006) Sodium intake and mortality in the NHANES II follow-up study. Am J Med 119, 275.e7-e14.

37. Dong J, Li Y, Yang Z et al. (2010) Low dietary sodium intake increases the death risk in peritoneal dialysis. Clin J Am Soc Nephrol 5, 240-247.

38. Saulnier P-J, Gand E, Ragot S et al. (2017) Urinary sodium concentration is an independent predictor of all-cause and cardiovascular mortality in a type 2 diabetes cohort population. J Diabetes Res 2017, 5327352. 
39. Tuomilehto J, Jousilahti $\mathrm{P}$, Rastenyte $\mathrm{D}$ et al. (2001) Urinary sodium excretion and cardiovascular mortality in Finland: a prospective study. Lancet 357, 848-851.

40. Stolarz-Skrzypek K, Kuznetsova T, Thijs L et al. (2011) Fatal and nonfatal outcomes, incidence of hypertension, and blood pressure changes in relation to urinary sodium excretion. JAMA 305, 1777-1785.

41. Nagata C, Takatsuka N, Shimizu N et al. (2004) Sodium intake and risk of death from stroke in Japanese men and women. Stroke 35, 1543-1547.

42. Ekinci EI, Clarke S, Thomas MC et al. (2011) Dietary salt intake and mortality in patients with type 2 diabetes. Diabetes Care 34, 703-709.

43. Costa APR, de Paula RC, Carvalho GF et al. (2012) High sodium intake adversely affects oxidativeinflammatory response, cardiac remodelling and mortality after myocardial infarction. Atherosclerosis 222, 284-291.

44. Gardener H, Rundek T, Wright CB et al. (2012) Dietary sodium and risk of stroke in the Northern Manhattan study. Stroke 43, 1200-1205.

45. Eckel RH, Jakicic JM, Ard JD et al. (2014) 2013 AHA/ACC guideline on lifestyle management to reduce cardiovascular risk: a report of the American College of Cardiology/
American Heart Association Task Force on Practice Guidelines. J Am Coll Cardiol 63, 2960-2984.

46. McLean RM (2014) Measuring population sodium intake: a review of methods. Nutrients 6, 4651-4662.

47. Aburto NJ, Ziolkovska A, Hooper L et al. (2013) Effect of lower sodium intake on health: systematic review and metaanalyses. BMJ 346, f1326.

48. Graudal N, Jürgens G, Baslund B et al. (2014) Compared with usual sodium intake, low-and excessive-sodium diets are associated with increased mortality: a meta-analysis. $\mathrm{Am}$ J Hypertens 27, 1129-1137.

49. Seo W \& Oh H (2010) Alterations in serum osmolality, sodium, and potassium levels after repeated mannitol administration. J Neurosci Nurs 42, 201-207.

50. Lother A, Fürst D, Bergemann S et al. (2016) Deoxycorticosterone acetate/salt-induced cardiac but not renal injury is mediated by endothelial mineralocorticoid receptors independently from blood pressure. Hypertension $\mathbf{6 7}$, 130-138.

51. Naska A, Lagiou A \& Lagiou P (2017) Dietary assessment methods in epidemiological research: current state of the art and future prospects. F1000Res $\mathbf{6}, 926$.

52. Lyu L-C, Hsu Y-N, Chen H-F et al. (2014) Comparisons of four dietary assessment methods during pregnancy in Taiwanese women. Taiwan J Obstet Gynecol 53, 162-169. 